\title{
Modeling of three-phase electric motor operation by the MATLAB system with deteriorated power quality in the 0.38 kV distribution networks
}

\author{
I.V. Naumov ${ }^{1}$, N.V.Savina ${ }^{2}$, M.V. Shevchenko ${ }^{3}$ \\ ${ }^{1}$ Irkutsk National Research Technical University, Amur State University \\ 2 Amur State University \\ ${ }^{3}$ Far East State Agricultural University
}

\begin{abstract}
One of the main operation modes that characterizes power quality in distribution networks is asymmetry of three-phase voltage system. Operation of an induction motor (IM) with disturbed voltage symmetry in the supply network can not be considered as a rated one. The system of voltages applied to the stator winding of IM under these conditions contains positive- and negative-sequence components. This worsens the performance characteristics of IM essentially. In order to balance the $0.38 \mathrm{kV}$ network operation and enhance the efficiency of the three-phase electric motor operation it is suggested to use a special balancing unit (BU) that minimizes the negative-sequence components of current and voltage. The operation modes of the obtained system "supply source - induction motor balancing unit" are simulated within the MATLAB software package of applied programs, which allows one to assess the impact of low quality of power on the operating characteristics of the electric motor and the efficiency of the balancing unit to increase the "durability" of the motor under the asymmetrical power consumption.
\end{abstract}

\section{Characteristic of asymmetric conditions}

The coefficient of negative-sequence voltages should be considered as the main index of power quality that characterizes the level of voltage asymmetry in threephase three-wire networks:

$$
K_{2 U}=\frac{U_{2}}{U_{1}},
$$

where $U_{2}, U_{1}$ - the negative- and positive sequence voltages.

Besides, the operation of induction motors under voltage asymmetry is complicated by the emergence of symmetrical components of the negative-sequence current. This causes additional power losses in the windings of rotor and stator which result in local overheating and affect greatly the motor lifetime and operation stability. Such losses for three-phase threewire (without zero wire) electric networks can be assessed using a coefficient of additional power losses [1]:

$$
K_{P}=\frac{\Delta P_{N E S .}}{\Delta P_{S I M .}}=\frac{3 I_{1}^{2} R_{1}+3 I_{2}^{2} R_{2}}{3 I_{1}^{2}}=1+K_{2 i}^{2},
$$

where $K_{2 i}=\frac{I_{2}}{I_{1}}$ - the coefficient of negativesequence current; $I_{2}, I_{1}$ - the negative- and positivesequence currents; $R_{2}, R_{1}$ - the negative- and positive- sequence resistances.

Numerous researches in the field of creation of imitating models of operation of the electric motor practically did not consider its work in the asymmetrical mode [2 - 11].

An aggregate impact of asymmetrical currents and voltages at motor operation in an asymmetric electric network causes a considerable change in its operating characteristics.

\section{A modeling tool}

In order to estimate real processes taking place in the motor during its operation under asymmetrical voltages the need arises to develop a mathematical model of these processes.

For modeling dynamic systems and devices we compose and solve the systems of differential equations which are most often of nonlinear character. The MATLAB system (MATrix LABoratory) with Simulink extension, in our opinion, is an ideal tool for implementation of the 
modeling. The said extension makes it possible to implement visually-oriented programming of the problems of automatic construction of a graphical model of the system or device, derive and solve the equations of state, present visually the results of modeling [12].

The MATLAB version 6.5 with Simulink 5.0 addin and library of the block of Sim Power Systems extensions, section Machines, were used to construct the models of the three-phase induction motor operation under voltage asymmetry in the supply network. The component Asynchronous Machine SI Units simulates an asynchronous electric machine in either motor or generator modes (determined by the sign of electromagnetic torque of the machine).

In the studied simulation model (Fig.1) ports A, B and $\mathrm{C}$ are the terminals of the machine stator winding. Port Tm is intended to supply drag torque; at terminal port $\mathrm{m}$ a vector signal forms. The signal includes 21 elements: currents, fluxes and voltages of rotor and stator in fixed and rotating coordinates, electromagnetic torque, number of shaft revolutions and its angular position. For convenience of extracting variables from the vector the SimPowerSystems library has the block Machines Measurement Demux (MMD).

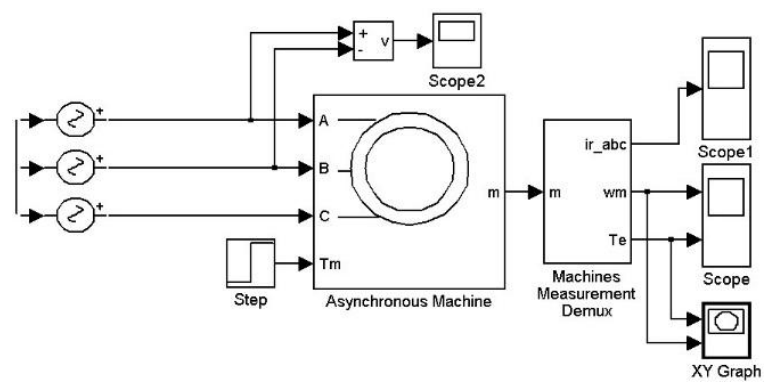

Fig.1. A scheme of simulation model of induction motor in the MATLAB system

The model of induction machine consists of a model of electric part represented by the fourth order state space and mechanical part being a second order system. All electric variables and parameters of the machine are reduced to the parameters of stator.

\section{Computational example}

The capacity of a simulated motor is $4 \mathrm{~kW}$, rated rotation frequency - $950 \mathrm{rpm}$, rated voltage of the three-phase network is $0.38 \mathrm{kV}$ with the frequency of $50 \mathrm{~Hz}$. The parameters of the studied motor were set in the block for parameter input. The performance characteristics of the motor were measured since the time of the motor startup at a rated load. Based on the data from ports $i r, a b c, w m$, Te of the MMD block we obtained the diagrams of currents in rotor, shaft angular velocity and electromagnetic torque as well as dynamic mechanical characteristics of the motor (Fig.2).

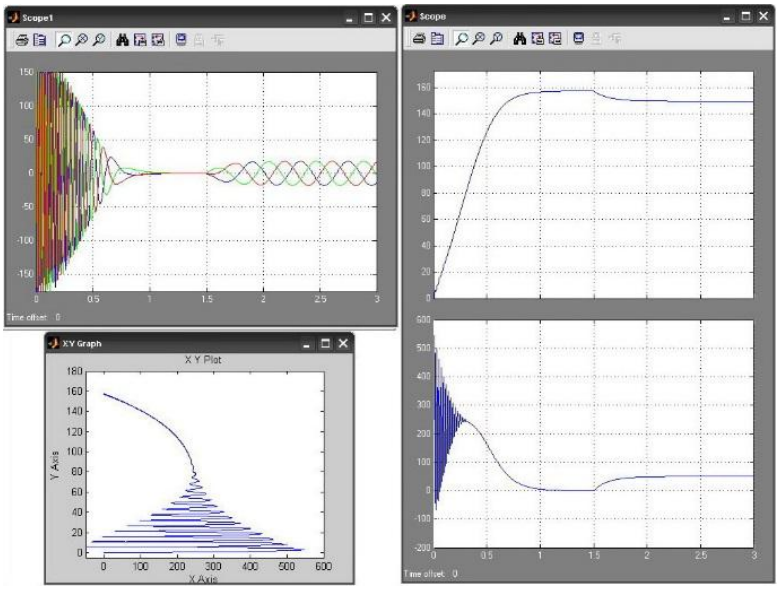

Fig.2. Dynamics of change in the motor performances at symmetrical voltage system

The symmetrizing device considerably reducing currents of the inverse sequence in the engine can serve as the most effective remedy of decrease in asymmetry of tension [13].

The parameters of balancing unit were calculated according to the largest set voltage asymmetry in the studied network [14]. According to the given initial data we conducted a series of experiments at different voltages of the power supply block of the induction motor. Here the change in the motor performances was studied both at connected and disconnected balancing unit.

The diagrams of the shaft angular velocity were analyzed as well as electromagnetic torque and dynamic mechanical characteristic of the motor.

The first experiment was conducted with symmetrical voltage system with rated parameters without balancing unit. The electromagnetic torque variations in the time range $0 \ldots . .0 .35 \mathrm{sec}$ (Fig.3) characterize the moment of motor start up. Then, after the speed is picked up and the operation mode is achieved, the operation of the motor stabilizes which is proved by the smooth section of the characteristics diagram. Electromagnetic field of the motor, which is generated by symmetrical voltage, has a regular radial form; the operation of the motor at a rated load is smooth without failures.

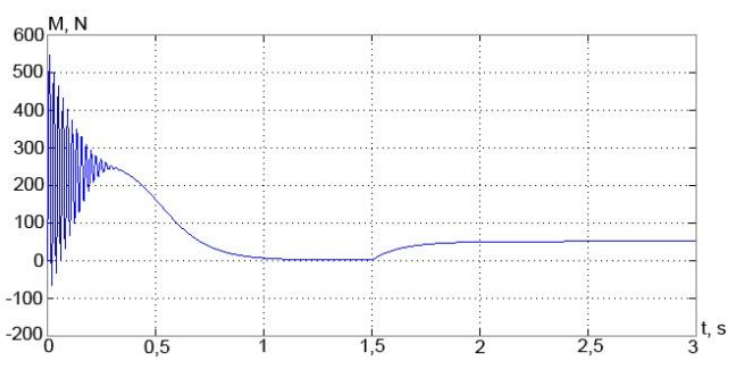

Fig.3. Dynamics of change in electromagnetic torque at a symmetrical voltage system in the supply network

The second series of experiments simulated different voltage asymmetry operation modes in supply network without balancing unit.

With increase in the asymmetry level the performance of the induction motor grows worse. In the operation mode with maximum asymmetry the 
increase in time of angular velocity acceleration was about $1 \%$, the capacity developed on the shaft of the motor decreased by $5 \%$. At the same time the operation of the motor itself becomes unstable which manifests itself through pulsation of velocity and electromagnetic torque (Fig.4). In order to determine more accurate relationship between the processes that occur during motor operation and coefficient of negative sequence voltage it is necessary to conduct additional research.

When the voltage asymmetry level $(\mathrm{Ku} 2=3.9 \%)$ was simulated we observed an essentially unstable electromagnetic torque and rotation speed of the motor rotor (Fig.4).

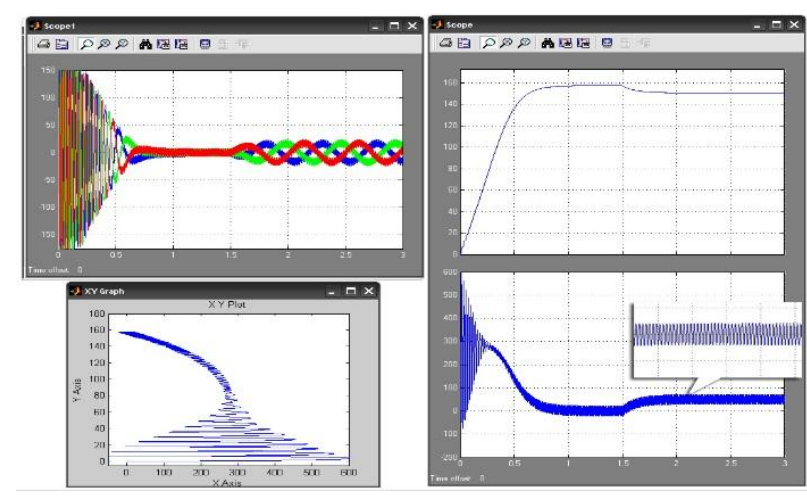

Fig.4. Dynamics of change in motor parameters at asymmetric voltage system in the network

This is caused by the change in the shape of stator and rotor magnetic fields from radial to elliptic under the influence of the negative sequence currents. This leads to emergence of a counteracting torque and decrease in available power of the motor.

The next series of experiments were conducted under the same level of voltage asymmetry in the supply network but with the balancing unit connected before the motor (Fig.5).

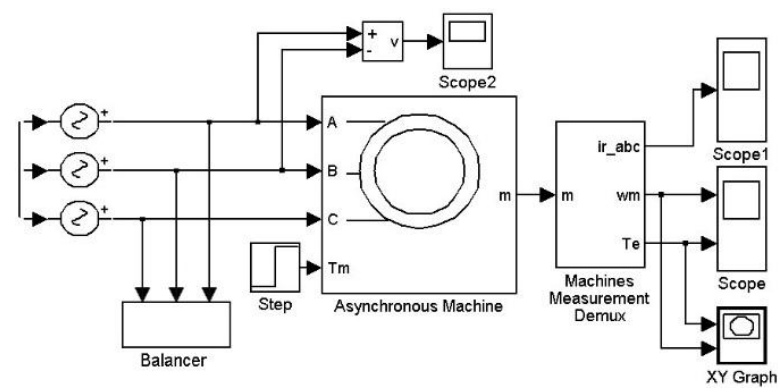

Fig.5. Flow chart of the simulation model of induction motor with the balancing unit in the MATLAB system

The balancing unit made it possible to compensate the voltage asymmetry in the supply network which affected positively the performance of the motor. For example when simulating the network asymmetry characterized by the negative sequence coefficient $\mathrm{K} 2 \mathrm{u}=3.9 \%$ with balancing unit before the motor the performances of the motor became better (Fig.6). The amplitude of electromagnetic torque pulsation decreased approximately 3 times, the value of the negative sequence voltage coefficient at the motor supply input decreased up to $1.1 \%$.

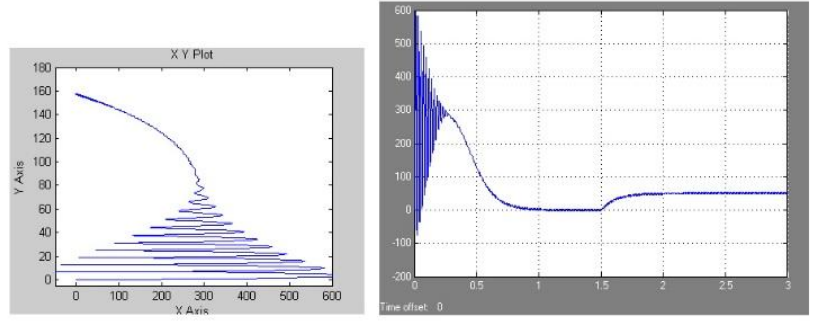

Fig.6. Dynamic mechanical characteristic and electromagnetic torque characteristic of the motor at asymmetry in the network with connected balancing unit.

\section{Conclusion}

Thus, the use of the simulation model in the MATLAB system allowed one in a rather short period to analyze the induction motor operation under different operating conditions of the supply network, reveal the extent of influence of the network voltage asymmetry, determine the effect of balancing unit connection. Hence, the use of balancing units for normalization of power quality and decrease of power losses enhances considerably the efficiency of three-phase electric motor operation in the public distribution networks.

The symmetrizing device is the most effective remedy of upgrading of operation of the three-phase motor in the conditions of asymmetry of tension

\section{References}

1. Kosoukhov F.D., I.V.Naumov Asymmetry of voltages and currents in rural distribution networks. Irkutsk: IS A A,2003. 257 p.

2. Shi K.L., Chan T.F., Wong Y.K., Ho S.L.. Modelling of the three-phase induction motor using SIMULINK/ Hong Kong Polytechnic University, Department of Electrical Engineerin// Int. J. Elect. Enging. Educ., Vol. 36, pp. 163172. Manchester, UK, 1999.

3. Chani S.N. Digital computer simulation of threephase induction machine-dynamics - a ganaralizd approach // IEEE Trans Industry Apple., No.1, pp. 106-114, 1988.

4. Waid S., Dunnigan M.V., Williams B.W. Modeling and simulation of induction machine vector control and rotor resistance indentificftion/ IEEE Trans. Power Electronicse, Vol. 12, No. 3, pp. 495-505, 1997.

5. Rrause P.C., Wasynezuk O., Sudholff S.D. Analysis of Electrik Mashinery, IEEE, 1995.

6. Krishnan R., Electric Motors Drives Modeling Analysis and Control, Publication Prentice Hall, India, 2002.

7. Bimal. K. Bose, Modern Power Electronics \& AC Drives, Publication Prentice Hall, India, 2003

8. Tang L., Rahman M.F., A new direct torque control strategy for flux and torque ripple reduction for induction motors drive - a Matlab/Simulink model // IEEE International 
Electric Machines and Drives Conference, 2001, pp. 884-890.

9. Leedy Aleck W. Simulink / MATLAB Dynamic Induction Motor Model for Use as a Teaching and Research Tool // International Journal of Soft Computing and Engineering (IJSCE), ISSN: 2231-2307, Volume-3, Issue-4, September, 2013.

10. Le-Huy H. Modeling and simulation of electrical drives using Matlab/Simulink and Power System Blockset // The 27th Annual Conference of the IEEE Industrial Electronics Society (IECON'01), Denver/Colorado, pp. 1603-1611.

11. Lakhya Jyoti Phukon, Neelanjana Baruah. A Generalized Matlab Simulink Model of a Three Phase Induction Motor // International Journal of Innovative Research in Science, Engineering and Technology. Vol. 4, Issue 5, May 2015.

12. MATLAB 6/6.1/6.5+Simulink 4/5. The Fundamentals of application. M.L SOLONPress. 2004. 768 p.

13. Naumov I.V. The symmetrizing device for three-phase four-wire network with adjustable parameters / Naumov I.V., Ivanov D.A., Podiyachikh S.V., Shpak D. //Patent for the useful model No. 61063 - It is published 10.02.2007 Bulletin No. 4, (in Russian).

14. Naumov I.V. Choice of parameters of balancing devices in the $0.38 \mathrm{kV}$ distribution networks / Naumov I.V., Belousova E.A. // Bulletin of KrasSAU, issue 1, 2017, No.1. -P.99-107. (in Russian). 